\title{
A century of apparent atmospheric transmission over Davos, Switzerland
}

\author{
D. Lachat • C. Wehrli
}

Received: 15 October 2011 / Accepted: 1 May 2012 /Published online: 3 July 2012

(C) Springer-Verlag 2012

\begin{abstract}
Pyrheliometer measurements have been carried out at the Physikalisches-Meteorologisches Observatorium Davos from 1909 to present which results in the longest stationary direct irradiance record worldwide. A variety of different instruments and measurement scales were homogenized and adjusted to the World Radiometric Reference. Following the pyrheliometric ratioing technique, a time-series of apparent atmospheric transmission was calculated and analyzed for possible trends in column transparency over Davos. In order to assess the trend found in the transmission record, the longterm annual cycle in apparent atmospheric transmission was used to deseasonalize the daily transmission data. The trends of early brightening, dimming and brightening were localized and found to be small but highly significant.
\end{abstract}

\section{Introduction}

Solar radiation and atmospheric transmission have been of increasing interest in climate research in the past decades. In this context, recent studies have observed decadal trends in solar radiation received at the Earth's surface. They claim a

D. Lachat $(\bowtie) \cdot$ C. Wehrli $(\bowtie)$

Physikalisch-Meteorologisches Observatorium Davos,

World Radiation Centre (PMOD/WRC),

Dorfstrasse 33,

7260 Davos-Dorf, Switzerland

e-mail: daniel.lachat@pmodwrc.ch

e-mail: christoph.wehrli@pmodwrc.ch

D. Lachat

Institute of Geography, University of Bern,

Bern, Switzerland

D. Lachat

Oeschger Centre for Climate Change Research,

Bern, Switzerland decrease of solar radiation of $6-9 \mathrm{~W} / \mathrm{m}^{2}$ from the 1950 s to the end of the 1980s followed by an ongoing recovery from the 1990s to present. These periods are referred to as Global Dimming and Global Brightening, respectively. Trends in cloud coverage and atmospheric transmission are prime focal points in the quest for possible causes of these changes. The observed trends in surface solar radiation are in line with trends in atmospheric transmission determined from pyrheliometer measurements (Wild et al. 2005).

Most of the observational pyrheliometer records begin measurements around 1950. The previously longest stationary surface solar radiation record was taken at Stockholm, beginning 1923. There, a significant trend of Global Dimming and Global Brightening was found (Wild 2009).

In recent years, Ohvril et al. (2009) have reconstructed a composite time-series using pyrheliometer data of six different stations in Eastern Europe covering together the period 1906-2007. There, the trend found in column transparency calculated from direct irradiance reflects the characteristics of the Global Dimming and Global Brightening found in global radiation records.

However, the pyrheliometer record of Davos, Switzerland, was examined by Hoyt and Fröhlich (1983) for the period 1909-1979. There, they have found no significant long-term trend in atmospheric transmission in direct irradiance. A re-analysis of the entire pyrheliometer record from 1909 to present will provide information on the magnitude and significance of a possible dimming and brightening in direct irradiance at Davos.

\section{Data}

The Physikalisches-Meteorologisches Observatorium Davos (PMOD) was founded in 1907 by Carl Dorno. The 
subject bioclimatology originated from the effort of Carl Dorno to describe mountain air and radiation properties (Dorno 1911). The observatory was situated at the Villa Dora above the village of Davos-Platz and moved to its current location in Davos-Dorf in 1976. The measurements presented in this paper were all retrieved from records kept in the archive of the PMOD.

\subsection{Radiometers and irradiance scales}

Carl Dorno started a program of extensive direct irradiance measurements, beginning with the purchase of the Angström pyrheliometer Nr. 128 from the University of Uppsala, Sweden in 1909. This compensation pyrheliometer was calibrated against the standard of the Ångström scale which was widely used in Europe (Dorno 1911).

Representing the Smithsonian Scale Revised 1913 used at the PMOD, the silver-disk pyrheliometer SI Nr. 50 was purchased and calibrated against the standard, the water stir pyrheliometer at the Smithsonian Observatory by Abbot. The efforts to take measurements with these instruments were considerable, since the operator had to read subscale divisions at an exacting timing accuracy (Mörikofer 1932).

Additionally, several relative direct irradiance measurement devices referred to as actinometers were also purchased. Among these, the Michelson actinometer Nr. 5100 (Dorno 1919) covered the longest operational period of all radiometers at PMOD from 1914 to 1969.

Most noteworthy is probably the Pyrheliograph "DornoThilenius", devised by Dorno, incorporating a thermopile receiver by $\mathrm{R}$. Thilenius in 1921, which was the first fully automated device to measure solar radiation (see Figs. 1 and 2). The pyrheliograph was tracking the sun by a clockwork. A mirror galvanometer recorded the measured solar intensity photographically. All relative radiometers (actinometers) were calibrated daily against the standard instruments (Dorno 1922). None of the pyrheliometers were equipped with filters. The instrument tube was daily checked by a human operator.

In the past, several radiation references or scales have been used in meteorology, namely the Ångström scale of 1905, the Smithsonian scale of 1913, and the International Pyrheliometric Scale of 1956 (WMO 2008). The current World Radiometric Reference (WRR) was established as the result of many comparisons of some 15 absolute radiometers of nine different types during the International Pyrheliometer Comparisons IV held at PMOD in 1975 (Fröhlich 1991). The WRR was adopted by the World Meteorological Organization (WMO) in 1977 and is realized by a group of seven absolute radiometers maintained at the PMOD.

The most prominent radiometers, their reference scales and the conversion factors to the WRR are shown in Table 1.

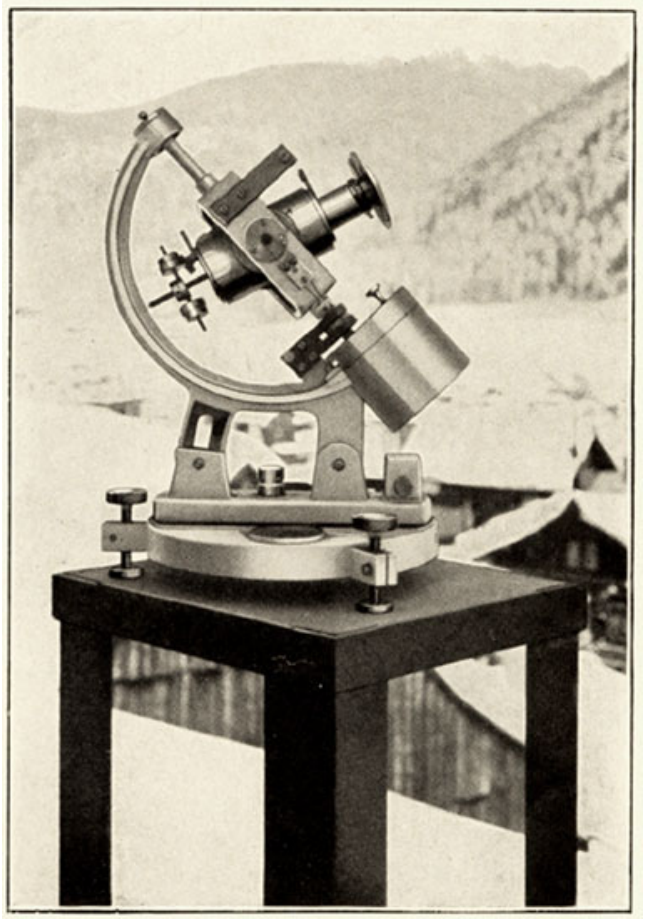

Fig. 1 Pyrheliograph "Dorno-Thilenius". Picture Courtesy of Monthly Weather Review, 50, October 1922

The periods attributed to the radiometers are not their operational time, which in most cases would be considerably longer, but the periods which entered in the pyrheliometer record. Conversion factors were taken from the WMO (2008).

\subsection{Quality screening and coverage}

The reconstructed irradiance series has been screened for implausible values that might have occurred from typographic errors in either the original documents or during manual digitization, by comparison to reasonable upper and lower boundaries. A simple radiative transfer model SMARTS2 (Gueymard 2001) was used to calculate expected irradiance values at a set of optical air masses for atmospheric parameters typically found at Davos. The theoretical upper limit was defined by pure Rayleigh atmosphere and ozone attenuation, i.e., containing no water vapor or aerosols, at an elevation of 1,600 m.a.s. Lower limits were calculated for different integrated water vapor contents derived as seasonal averages of GPS retrievals at Davos. The input values of integrated water vapor are $0.6 \mathrm{~atm} \mathrm{~cm}$ in the winter season, $1.1 \mathrm{~atm} \mathrm{~cm}$ in the transition season, and $1.6 \mathrm{~atm} \mathrm{~cm}$ in the summer season. In order to include volcanic events, an additional lower limit was applied using input values, which represent the atmospheric conditions of the summer 1992 after the eruption of Mt. Pinatubo. These values are $2.0 \mathrm{~atm} \mathrm{~cm}$ IWV and $0.3 \mathrm{AOD}$ at 
Fig. 2 Photographic strip of the Pyrheliograph "DornoThilenius" recorded on August 12, 1944. The baseline represents the zero measurements, the arch represents the radiation intensity. Additional the marks in-between indicate filter measurements splitting the total irradiance into spectral bands. Picture Courtesy of Archive PMOD/WRC

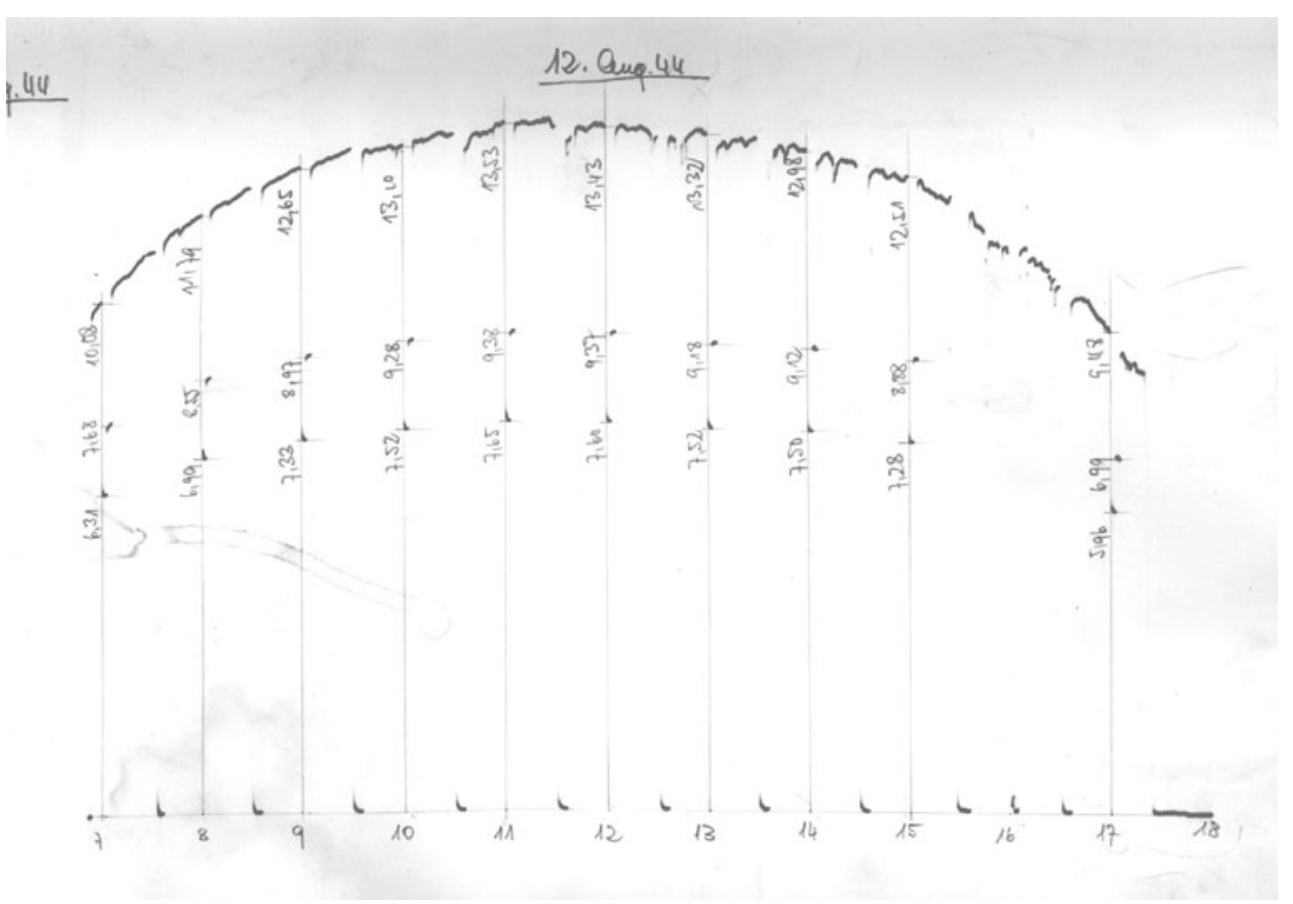

$500 \mathrm{~nm}$. From a total of roughly 170,000 data points, about 132,000 remain in the dataset after this screening (see Fig. 3).

Data coverage of the pyrheliometer record reflects the different measurement regimes at the PMOD. After 1960, observations carried out on each clear-sky day were replaced by sporadic measurements for calibration purposes, which resulted in far lower data coverage in terms of measurement days. The digital data available since 1990 show a much enhanced coverage in terms of daily measurements, the coverage in terms of days did not increase significantly. Interestingly, the data screening described above shows a different effect on these measurement regimes. While daily observations of the historical period from 1909 to 1960 as well as modern day data from 1990 onward suffer considerably from data loss, the data from the intermediate calibration period from 1960 to 1990 is less affected. This reflects the high quality of the data of this period, which had to meet calibration standards with cloud-free sun conditions (see Fig. 4).

\section{Method}

\subsection{Pyrheliometric ratioing technique}

Absolute atmospheric transmission is defined as the ratio of the solar irradiance at air mass 1 , which corresponds to the atmospheric mass at sea level and zenith direction, and the irradiance at the top of the atmosphere. The absolute transmission value cannot be calculated at Davos as air mass 1 is never reached. The minimal air-masses at culmination for the latitude of Davos are between 1.088 on summer and 2.937 on winter solstice. The air masses $1,2,3,4$, and 5 correspond to the solar elevations of $90^{\circ}, 29.9^{\circ}, 19.3^{\circ}$,
Table 1 Some of the most prominent radiometers used in the record of Davos, their period within the time-series of Davos, the corresponding scales of reference and the conversion factors to the WRR

\begin{tabular}{lllc}
\hline Period & Radiometer & Scale & Conversion factor \\
\hline $1909-1926$ & Ångström Nr. 128 & Smithsonian revised 1913 & 0.977 \\
$1914-1956$ & Michelson Nr. 5100 & Smithsonian revised 1913 & 0.977 \\
$1930-1946$ & Pyrheliograph Dorno-Thilenius & Smithsonian revised 1913 & 0.977 \\
$1936-1956$ & Ångström Nr. 210 & Smithsonian revised 1913 & 0.977 \\
$1957-1969$ & Michelson Nr. 5100 & IPS-56 & 1.026 \\
$1957-1972$ & Ångström Nr. 210 & IPS-56 & 1.026 \\
$1970-1972$ & PACRAD-III & IPS-56 & 1.026 \\
$1973-1980$ & PACRAD-III & WRR & 1.000 \\
$1976-1989$ & PMO-2 & WRR & 1.000 \\
$1990-2010$ & WSG & WRR & 1.000 \\
\hline
\end{tabular}




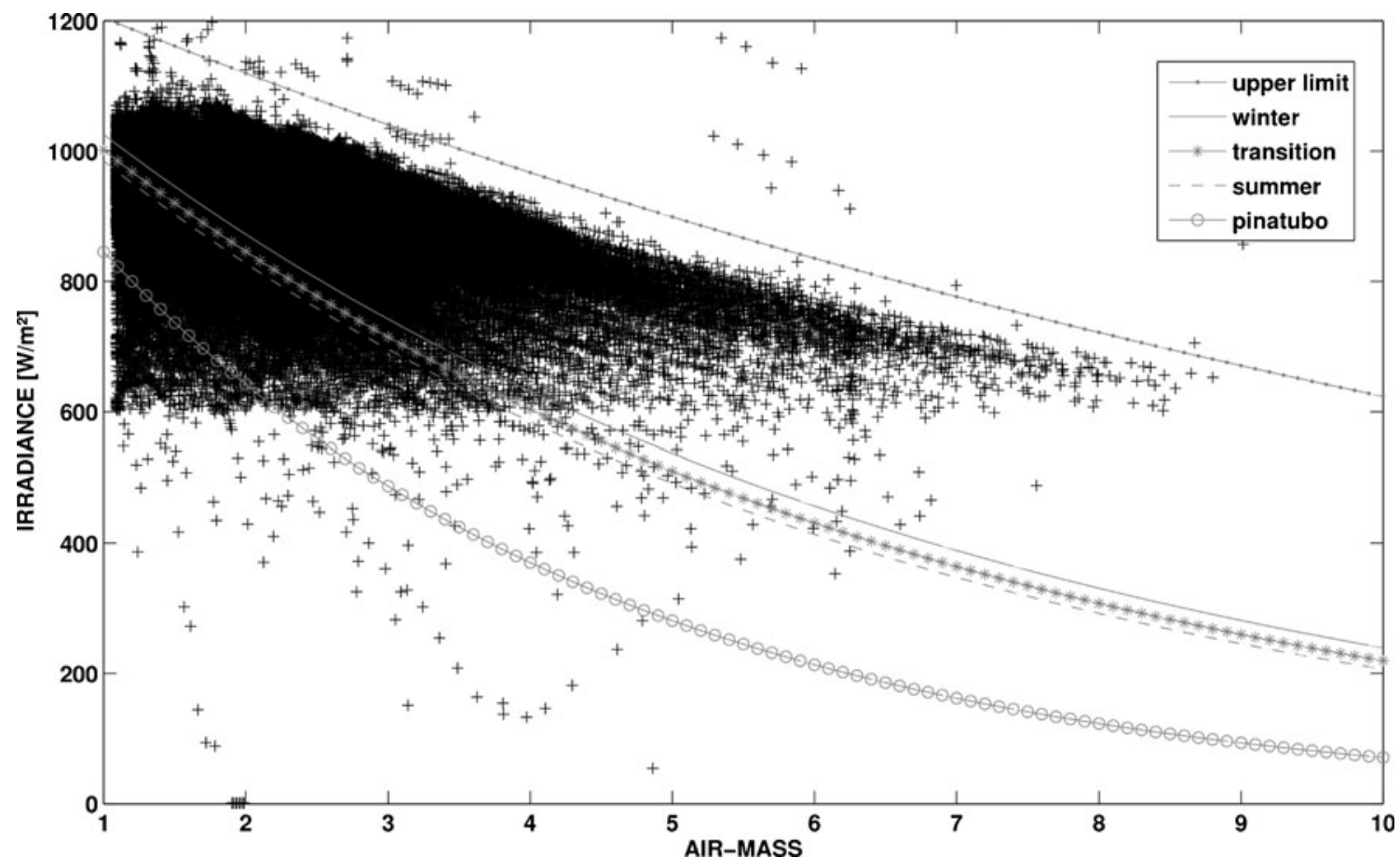

Fig. 3 Irradiance data of the entire radiation record of Davos (crosses), upper limit, and seasonally distinct lower limits calculated with the SMARTS2-radiative transfer model. The total of roughly 132,000 data points before the selection is shown. In the modern day epoch, irradiance values below $600 \mathrm{~W} / \mathrm{m}^{2}$ were measured, but not archived

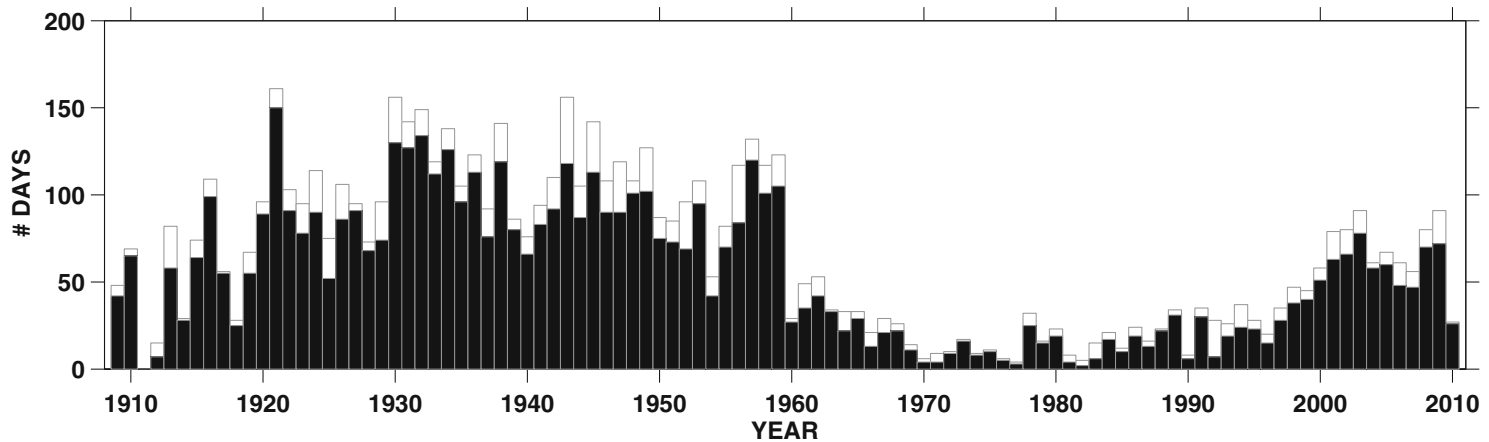

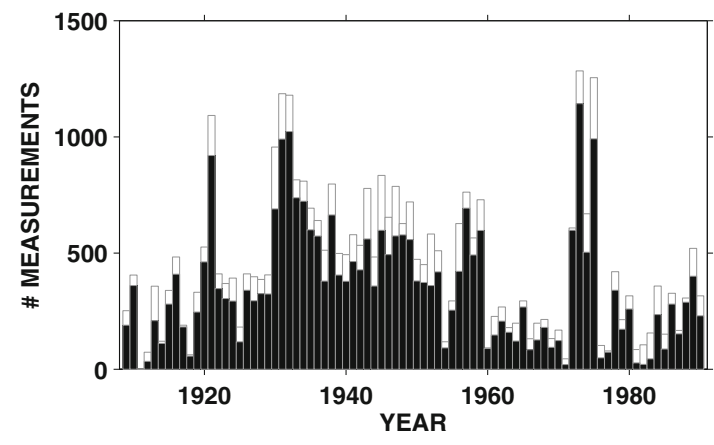

Fig. 4 Above: Data coverage in terms of days of the total record (light bars) and after data screening (dark bars). Below data coverage for the historic (left panel) and modern (right panel) period in terms of

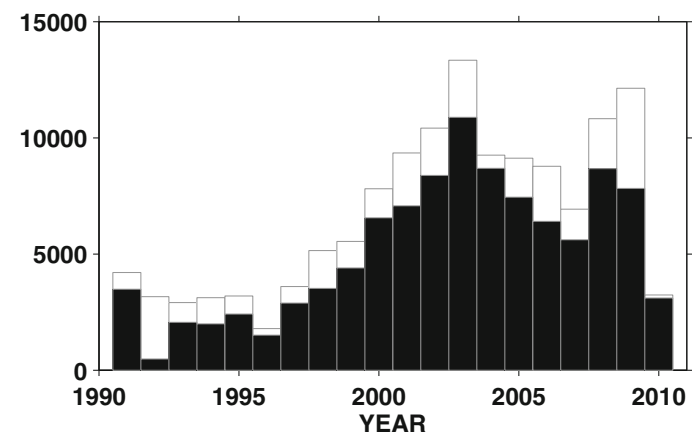

measurements of the total record (white bars) and after data screening (black bars). Apparently, no pyrheliometric measurements were taken in 1911 
$14.3^{\circ}$, and $11.3^{\circ}$, respectively, when calculated by Kasten and Young (1989) formula.

Air mass 1 irradiance can be estimated by fitting the irradiance values as function of air mass and extrapolating the fitted function. In order to reduce the error of the fit and of the estimation of transmission, the pyrheliometric ratioing technique applies the ratio of the irradiances at fixed airmasses. Instead of the simple ratio of two air masses, Hoyt (1981) has used the average of several ratio pairs as follows:

$q=\frac{1}{3} \sum_{m=3}^{5} \frac{I_{m}}{I_{m-1}}$

where $I_{m}$ is the irradiance corresponding to air mass $m$.

In the SMARTS2 radiative transfer model, different input data sets were created and the resulting transmission compared to the reference transmission. The ratio of the air masses $m=2$ to $m=1$ has shown the best agreement with the modeled transmission. Higher air mass ratios (e.g., $I_{4} / I_{3}$ ) as well as the average of several ratios tend to artificially increase the estimated transmission. This reduces (1) to:

$q=I_{m} / I_{m-1}$

where $m=2$ and $q$ is the so-called apparent atmospheric transmission as opposed to the absolute vertical column transmission. It follows that:

$q=I_{2} / I_{1}$

as it was presented by Hoyt and Fröhlich (1983).

The pyrheliometric ratioing technique varies in its form, particularly the specific air mass ratios and the mathematical function chosen. Ellis and Pueschel (1971), who first applied this method, used an exponential function to fit the irradiance data, while Hoyt and Fröhlich (1983) have chosen a parabolic function to fit the irradiance data of Davos.

In this study, we compared the following applications of the pyrheliometric ratioing technique:

1 Parabolic fit with the top of the atmosphere (TOA) irradiance at air mass 0 fixed in the fitting model, $y=l_{0} \times \mathrm{bm} \times \mathrm{cm}^{2}$

2 Exponential fit, $y=a \times e^{(\mathrm{bm})}$

3 Exponential fit, but with TOA irradiance as an additional node at air mass 0

4 Exponential fit with the TOA irradiance fixed in the fitting model, $y=l_{0} \times e^{(\mathrm{bm})}$

where $y$ denotes the fit to the irradiance data.

In a method comparison, the performance of the methods 1-4 was evaluated regarding the adequacy and stability of the estimation of apparent transmission (see Fig. 5). The daily transmission values obtained by applying different ratioing techniques show that the methods 1 and 2 produce rather unstable results which are strongly dependent on the distribution of measurements within a day and also strongly influenced by irregularities such as cirrus clouds. In the historical period from 1909 to 1959 , the clarity of the solar disk was evaluated by a human meteorologist. Unfortunately, this record has not been digitized. In the calibration period from 1959 onward, the clearness of the solar disk was also evaluated by a human observer to ensure stable atmospheric conditions for the instrument comparisons, but the evaluations were not archived.

Method 3 offers the possibility to estimate apparent transmission from days with only a single pyrheliometer measurement. This is crucial for the coverage of the resulting transmission series as there are a considerable amount of days in the pyrheliometer record with less than three measurements a day.

However, the TOA irradiance as an additional node at air mass 0 is weighted differently depending on the number of daily measurements. As previously seen in Fig. 4, the number of daily measurements increases significantly in the modern epoch, thus reducing the contribution of the additional node at air mass 0 to the fitted function and artificially increasing the daily transmission values. This effect can easily be seen in Fig. 5 bottom right, where the transmission values after day number 4,700, roughly corresponding to the year 1990, are significantly higher than the values of the historical period.

Method 4 was found to be most suitable for evaluating both days with only few measurements and days with very many measurements simultaneously. For consistency reasons, estimation of apparent transmission over the entire pyrheliometer record is performed by the same method.

\subsection{Seasonal weighting}

Apparent atmospheric transmission over Davos is subject to a pronounced annual cycle that is anticorrelated with cycles of integrated water vapor content and aerosol concentration (see Fig. 6). This significant annual variation being much larger than the expected trend makes it necessary to account for differences in seasonal coverage over the years. In other words, the daily transmission values need to be deseasonalized before any trend analysis.

From 1970 to 1990 , measurements were predominantly taken on clear autumn days for calibration purposes. During this period, seasonal coverage of annual means show significant differences from the distribution of seasonality before and afterwards (see Fig. 7).

For numerical illustration we consider a seasonal soundly distributed year such as 1927, where the percentage of seasons in terms of days is as follows: spring (MAM) $25.27 \%$, summer (JJA) $27.47 \%$, autumn (SON) $21.97 \%$, and winter (DJF) $25.27 \%$. The annual mean of apparent transmission using all the available data yields 0.8266 . 

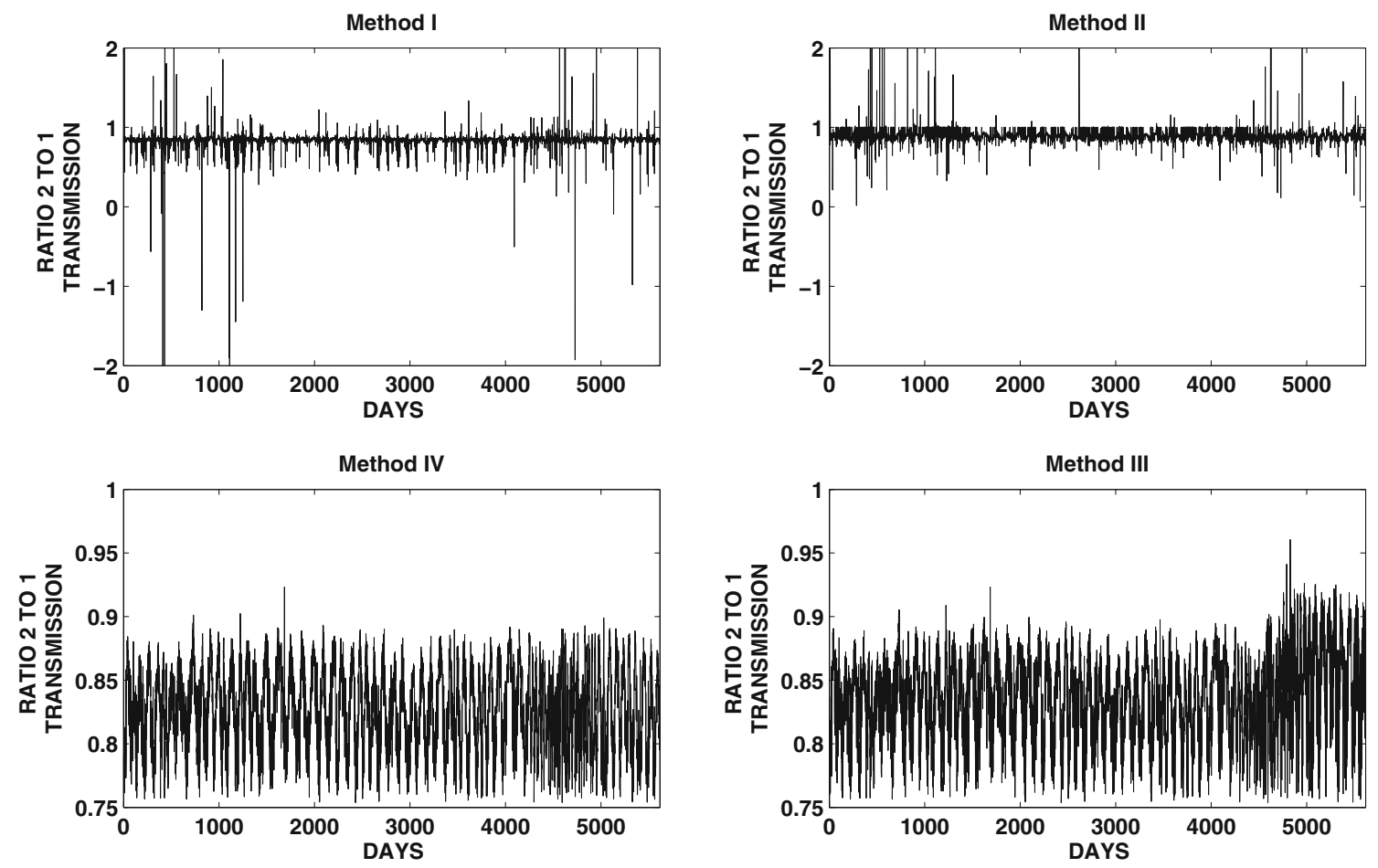

Fig. 5 Daily apparent transmission of the entire Davos record applying four different methods, corresponding to the transmission series $1-$ 4 (clockwise from upper left). Note the different $y$-axes which represent

If we introduce an artificial season bias and select only winter data, an apparent transmission value of 0.885 is obtained, for summer data only it is 0.7841 , respectively. The spread of 0.1 apparent transmission, which is more than $12 \%$ of the seasonally well distributed annual mean, emphasizes the effect of a seasonal bias.

The annual coverage in terms of days is biased in favor of the historical period (see Fig. 4, upper panel). Therefore, the

the interval of the resulting transmission values. The spikes in the upper panels are due to ill-fitted irradiance values and the corresponding miscalculated transmission value

whole transmission series is divided into five 20-year segments from which five annual cycles are calculated. These are averaged arithmetically in order to avoid an annual cycle representing predominantly the historical period. The resulting annual cycle shown in Fig. 6 is used to deseasonalize the pyrheliometer record. The long-term daily means of atmospheric transmission are subtracted from the individual daily transmission values and the residuals analyzed regarding decadal trends.

Fig. 6 Mean annual cycle of apparent atmospheric transmission at Davos derived from daily means over the entire pyrheliometer record. The bold smooth line is a running average over 31 days; the dashed lines represent the $2 \sigma$ confidence regions

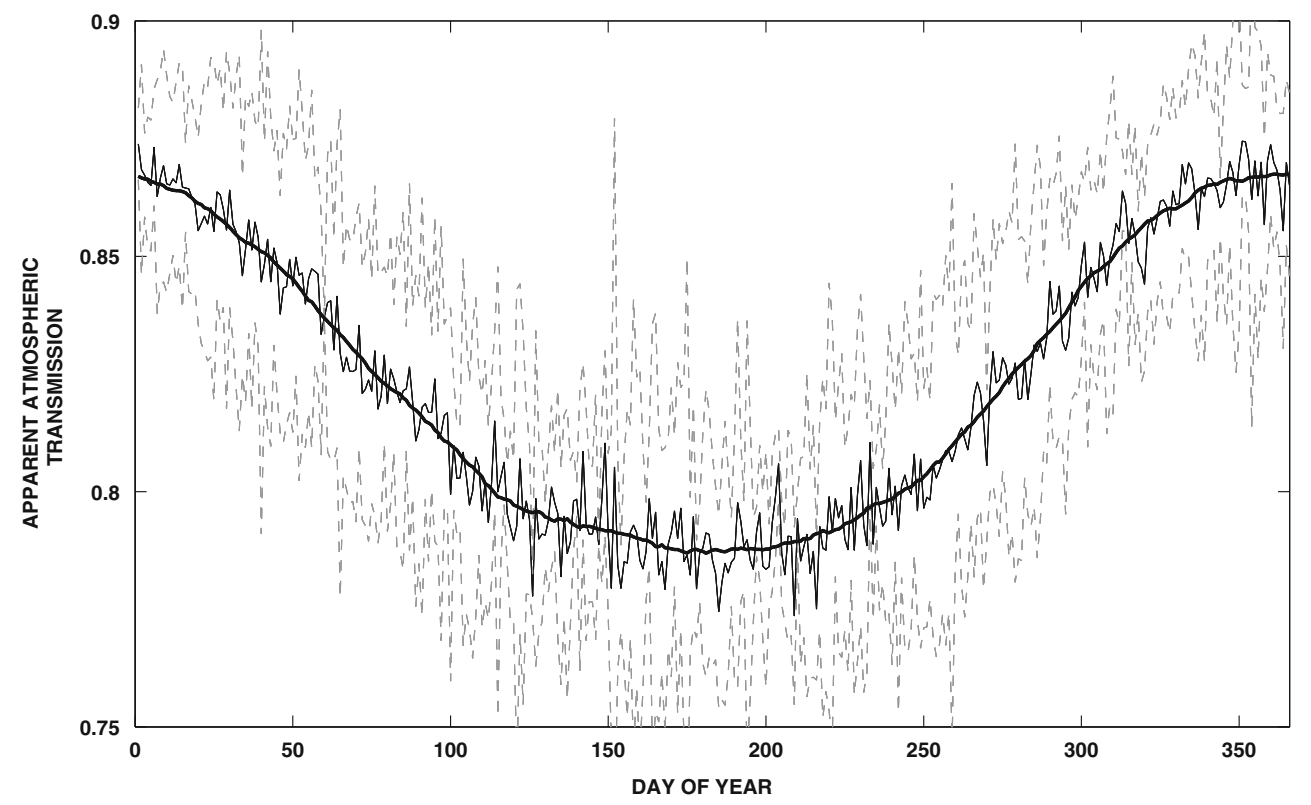


Fig. 7 Seasonal coverage in percent of total days after quality screening. The seasons are structured by meteorological seasons as follows: spring (MAM, black), summer (JJA, dark gray), autumn (SON, light gray), and winter (DJF, white). No pyrheliometric measurements were taken in 1911

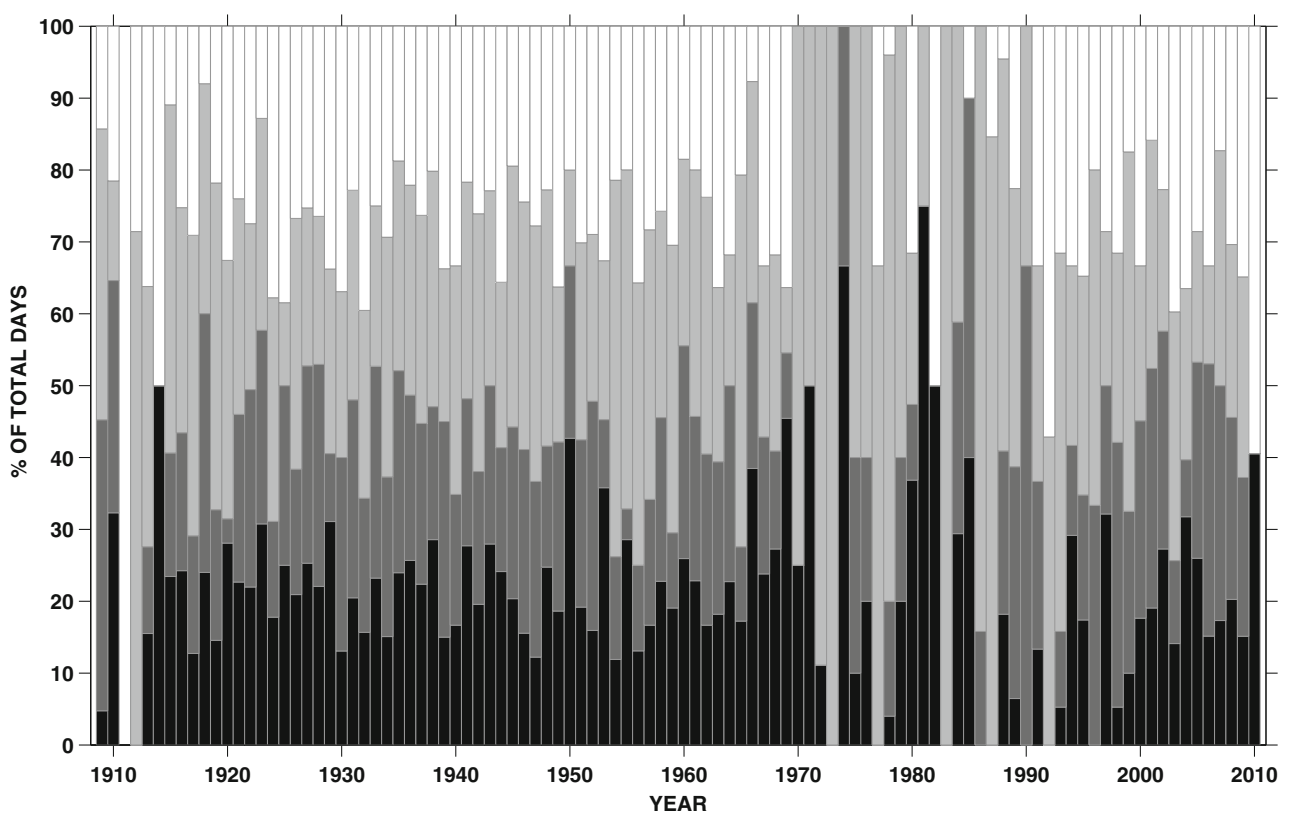

\section{Results}

\subsection{Deseasonalized transmission series}

Annual means of apparent atmospheric transmission over Davos from 1909 to 2010 are shown in the upper panel of Fig. 8. The irradiance data set used as input was created applying the lower limit representing the atmospheric conditions of the summer of 1992 after the eruption of Mt. Pinatubo. The $2 \sigma$ confidence regions include the annual variability as well as the variable seasonal data coverage. The long-term mean of the apparent atmospheric transmission is 0.8099 . The annual means of the residuals of daily apparent transmission to the long-term annual cycle presented in the previous chapter are shown in the lower panel of Fig. 8. As expected, the confidence region is reduced by elimination of the annual variability, and comprises mostly the statistical uncertainty.

A moving 31-year trend was applied to the time-series of residuals to the 100-year climatology. The irradiance data set used as input was created applying the seasonally distinct lower limits representing average clear-atmosphere conditions. With an interval of 1 year, this yields 72 trend lines, which are shown in the upper panel of Fig. 9. The periods of these trend lines are: 1909-1940, 1910-1941, ..., 1979-2010. The corresponding slopes of these trend lines
Fig. 8 Upper panel annual means of apparent atmospheric transmission. Lower panel Annual means of residuals to 100-year climatology. The long-term mean is represented by the solid line, $2 \sigma$ confidence region is represented by the two dashed lines
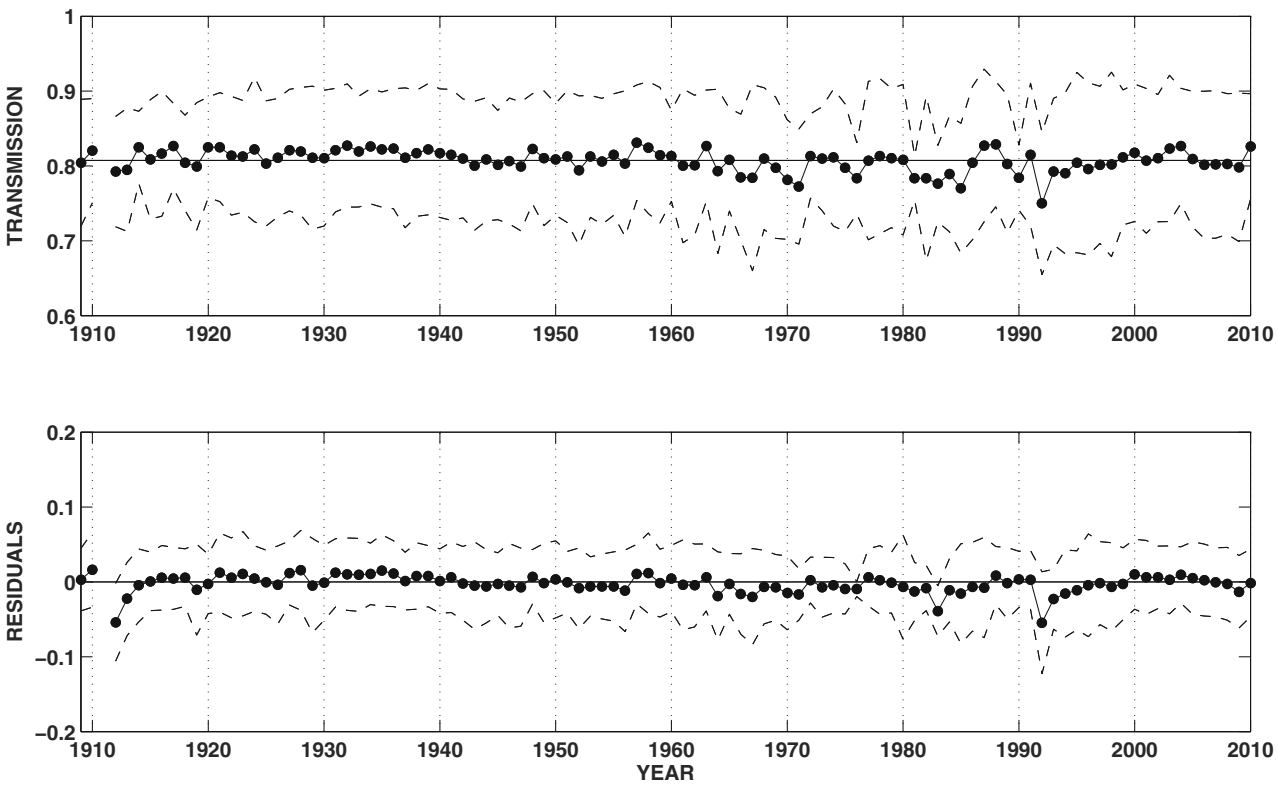
Fig. 9 Upper panel Annual means of the residuals to the 100-year climatology and 30year moving trend lines. Lower panel corresponding slopes of the 31-year moving trend lines
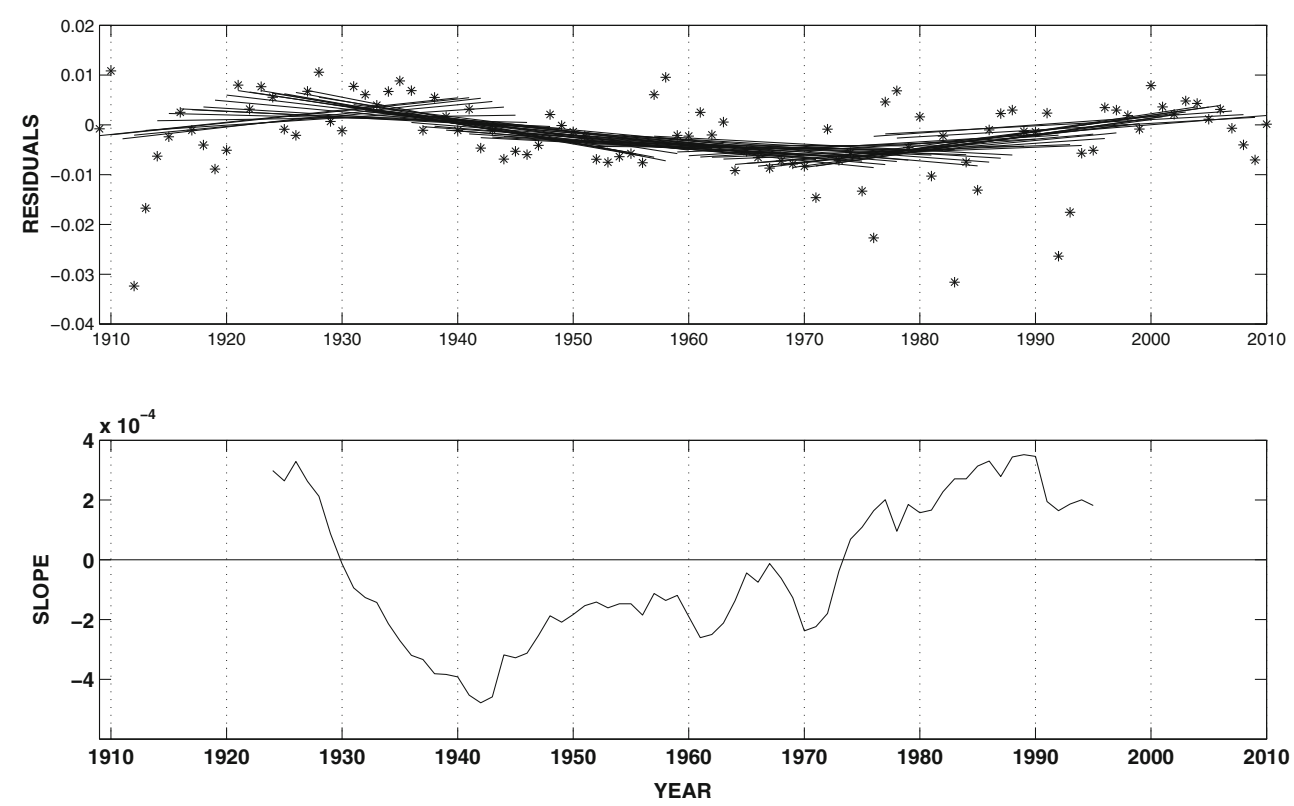

are shown in the lower panel of Fig. 9, ranging from 1924 to 1995. The change in sign of these trend lines is used to define the time periods for which linear trends are applied. As a result, the time-series is divided into three periods: A period of Early Brightening up to 1929, a Dimming period covering the years 1930 to 1973 and a Brightening period, from1974 onward.

A linear regression was applied for these periods. The means of the annual residuals of these sequences are -0.0013 for the Early Brightening period up to $1929,-0.0018$ for the Dimming period from 1930 to 1973 and -0.0034 for the Brightening period from 1974 onward. The slopes of the trend lines per decade and the errors of the coefficients are $(4.5 \pm$ $2.9) 10^{-3},(-2.8 \pm 0.6) 10^{-3}$, and $(1.9 \pm 1.0) 10^{-3}$, respectively.

\subsection{Seasonal analysis}

In order to detect seasonal differences of the trends presented in the previous section, the transmission-series was separated in half-years. The half-years were defined as the period above the mean of the annual cycle shown in Fig. 6 and the period below the mean, respectively. The warm halfyear thus corresponds to the day numbers 80-276 which includes 2,372 days in the transmission record, the cold
Fig. 10 Upper panel seasonal means of apparent atmospheric transmission and 30-year moving trend lines. Lower panel corresponding slopes of the 31year moving trend lines
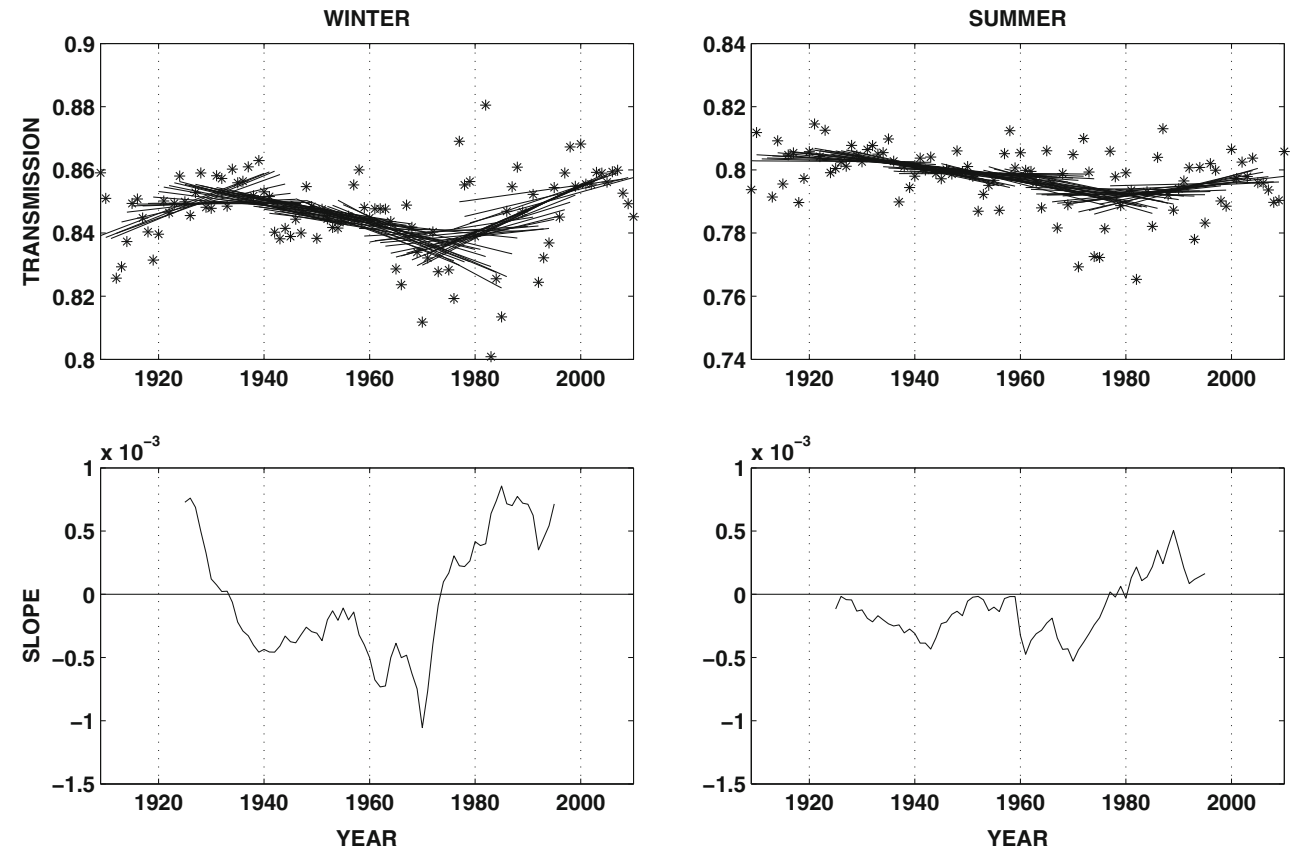
half-year which covers the rest of the year, including 2,692 days.

The 31-year moving trends and the slopes of the moving trend lines are shown in Fig. 10. For the winter season, the periods separated by the change in sign of the slopes of the trend lines are the early period up to 1933 , the Dimming period from 1934 to 1973 and the Brightening period from 1974 onward. Interestingly, the turnover point from Dimming to Brightening matches with the one determined from the deseasonalized transmission series.

For the warm half-year, there is no clear distinction between an early period and the subsequent Dimming period. Also, the turnover point between Dimming and Brightening cannot be clearly defined by the sign change of the slopes of the trend lines, but is assumed to be the year 1979. Therefore, the warm half-year-record is only split into two periods, an early period reaching from 1909 to 1978 and a Brightening period covering the years 1979 to 2010.

For the cold half-year, the means of the annual transmission values of these sequences are 0.847 for the Early Brightening period up to 1933, 0.845 for the Dimming period from 1934 to 1973, and 0.848 for the Brightening period from 1974 onward. The slopes of the trend lines per decade are $(6.2 \pm$ $2.6) 10^{-3},(-5.2 \pm 1.2) 10^{-3}$, and $(5.2 \pm 2.6) 10^{-3}$, respectively.

\section{Conclusions}

The 100-year pyrheliometer series from 1909 to 2010 at Davos were compiled and analyzed for secular trends. The data was carefully screened and homogenized.

The pyrheliometer series was subject to inhomogeneity due to varying seasonal coverage. Therefore, deseasonalizing of the original transmission series with a 100 -year climatology was necessary. Figure 8 shows a reduction of the confidence region. This is nicely illustrated in the year 1982 which consists of only few measurements in July and January resulting in a very large standard deviation in the annual mean before deseasonalizing.

The deseasonalized annual means generally converged towards the climatological mean, as seen in the years 1924 and 2003. This is a direct consequence of the elimination of the seasonal bias. This effect is most prominent in the period from 1970 to 1990 , where the seasonal coverage is particularly ill distributed. We assume that the negative bias of the year 1983 as well as the years 1992 and 1993 are reflecting impacts of the volcanic eruptions of El Chichón in 1982 and Mt. Pinatubo in 1991.

The moving trend has shown to be useful in identifying the inflection points of the secular trends (e.g., the changeover from Dimming to Brightening). Indeed, three periods were localized. The trends of Early Brightening, Dimming, and Brightening in direct irradiance are small, but highly significant. For both the deseasonalized and the seasonal transmission series, the Dimming period is most significant. These results are contradictory to the previous results found by Hoyt and Fröhlich (1983) who found no significant trend in the period 1930-1968. The authors suspect that the differences might arise from the different time periods analyzed. Possibly, the periods of Early Brightening and Dimming may annihilate each other, resulting in no significant trend over the period 1930-1968.

The differences in the half-year trends suggest that the phenomenon of Dimming and Brightening is predominantly manifested in the cold half-year, warm half-year trends are inconclusive. Further work will focus on a segmentation of transmission in factors accounting for water vapor and aerosol particles.

Acknowledgments The support from the Swiss National Science Foundation (grant \#200021-124924), as well as the constructive comments by two anonymous reviewers is acknowledged. Meteorological data were kindly provided by MeteoSwiss.

\section{References}

Dorno C (1911) Studie über Licht und Luft des Hochgebirges. Vieweg Dorno C (1919) Physik der Sonnen- und Himmelsstrahlung. Strahlentherapie IX:489-491

Dorno C (1922) Progress in radiation measurements. Monthly Weather Review 50:515-521

Ellis H, Pueschel R (1971) Solar radiation: absence of air pollution trends at Mauna Loa. Science 172:845-846

Fröhlich C (1991) History of solar radiometry and the world radiometric reference. Metrologia 28:111-115

Gueymard C (2001) Parameterized transmittance model for direct beam and circumsolar spectral irradiance. Solar Energy 71:325346

Hoyt D (1981) Apparent atmospheric transmission using the pyrheliometric ratioing technique. J Appl Optics 18(15):2530-2531

Hoyt D, Fröhlich C (1983) Atmospheric transmission at Davos, Switzerland 1909-1979. Climate Change 5:61-71

Kasten F, Young AT (1989) Revised optical air mass tables and approximation formula. Appl Optics 28:4735-4738

Mörikofer W (1932) Neue Vergleichungen zwischen dem silver-diskpyrheliometer und dem Angström-pyrheliometer. Internat Strahlungskommission, Anlage V: 43-44

Ohvril $\mathrm{H}$ et al (2009) Global dimming and brightening versus atmospheric column transparency, Europe, 1906-2007. J Geophys Res 114:1-17, D00D12

Wild M (2009) Global dimming and brightening: a review. J Geophys Res 114:1-31, D00D16

Wild M, Ohmura A et al (2005) From dimming to brightening: decadal changes in solar radiation at earth's surface. Science 308:847-850

WMO (2008) Guide to meteorological instruments and methods of observations. WMO-No. 8 (Seventh edition) 